\title{
Contact allergy to thiurams: multifactorial analysis of clinical surveillance data collected by the IVDK network
}

\author{
Wolfgang Uter $\cdot$ Janice Hegewald $\cdot$ Annette Pfahlberg $\cdot$ \\ Holger Lessmann • Axel Schnuch · Olaf Gefeller
}

Received: 23 July 2009 / Accepted: 15 December 2009 / Published online: 30 December 2009

(C) The Author(s) 2009. This article is published with open access at Springerlink.com

\begin{abstract}
Purpose To analyse the association between occupation (represented by job title) and contact allergy to thiuram vulcanising agents based on data of a clinical registry (IVDK, www.ivdk.org).

Methods Clinical, demographic and allergy patch test data of all patients tested between 1992 and 2006 with the thiuram mix (1\% in petrolatum) as part of the baseline series was analysed $(n=121,051)$. Poisson regression analysis was used to quantify the association between different occupations (and other relevant factors) and a positive patch test reaction to the thiuram mix. Furthermore, the time trend of sensitisation prevalence was analysed in highrisk occupational subgroups identified.

Results In comparison to a largely unexposed reference group (office workers and teachers), rubber manufacturers had a significantly elevated risk (prevalence ratio (PR): 5.1, 95\% confidence interval (CI) 2.0-10.5). However, health care workers such as physicians and dentists (PR: 3.8, 95\% CI: 3.0-4.8) or nursing staff (PR: 3.0, 95\% CI: 2.5-3.6) as well as meat and fish processors (PR 3.5, 95\% CI: 2.2-5.3) and cleaners (PR 3.1, 95\% CI: 2.5-3.8) were found to have
\end{abstract}

The centres contributed data to this analysis have been listed in "Appendix".

W. Uter $(\bowtie) \cdot$ J. Hegewald $\cdot$ A. Pfahlberg $\cdot$ O. Gefeller

Department of Medical Informatics,

Biometry and Epidemiology,

University of Erlangen/Nürnberg,

Waldstr. 6, 91054 Erlangen, Germany

e-mail: wolfgang.uter@imbe.med.uni-erlangen.de

H. Lessmann · A. Schnuch

Information Network of Departments of Dermatology,

University of Göttingen, von-Siebold-Str. 3,

37075 Göttingen, Germany a high sensitisation risk as well. In case of health care workers, a significant downward trend during the study period was observed; while in food processors and cleaners, sensitisation prevalence remained largely stable.

Conclusion The adjusted multifactorial analysis identified occupations yet unknown to be associated with elevated thiuram contact allergy risk, e.g., food processors and cleaners. Thus, (i) further in-depth research can be targeted and (ii) efforts to prevent sensitisation to thiurams focussed, e.g., by limiting thiuram concentrations in products to a residual level which is technically inevitable.

Keywords Contact allergy $\cdot$ Rubber $\cdot$ Thiurams $\cdot$ CAS 97-77-8 · CAS 97-74-5 · CAS 137-26-8 · CAS 94-37-1 . Dithiocarbamates $\cdot$ Occupation $\cdot$ Time trend

\section{Introduction}

Among the various substances known to cause occupational allergic contact dermatitis, additives to rubber comprise a conspicuous and meaningful subgroup. The additives are either remnants from the production process, e.g., vulcanisation accelerators, or added to enhance the technical properties of the final product, such as plasticisers, colours, antioxidants or antiozonants (Belsito 2000). The thiurams are regarded as the most important class of contact allergens among the vulcanizers, partly due to cross-reactivity (-allergy) with corresponding dithiocarbamates, which are used for similar purposes. Patch testing is performed with a screening mix of tetraethylthiuram disulphide (CAS 97-77-8), tetramethylthiuram monosulfide (CAS 97-74-5), tetramethylthiuram disulphide (CAS 137-268) and dipentamethylenethiuram disulphide (CAS 94-37-1) at $0.25 \%$ each, i.e., a total concentration of $1 \%$ incorporated 
into petrolatum as carrier. The thiuram mix is part of all national and international standard series known to us. Hence, virtually all patients who are patch tested are exposed to the thiuram mix.

Such general diagnostic application enables the analysis of occupational (and other) risk factor not biased by selective application of the allergen to certain subgroups of patients undergoing patch testing-notwithstanding the issue of selection from the (working) population into the group of patients patch tested (see "Discussion"). Data collected by the Information Network of Departments of Dermatology (IVDK, www.ivdk.org) was retrospectively analysed, regarding the association between contact allergy to the thiuram mix and occupational exposure and other important factors, respectively.

\section{Methods}

The IVDK, a contact allergy surveillance network in Germany, Switzerland and Austria, has been described elsewhere. Briefly, results of all patients patch tested in the participating departments are electronically recorded, along with important demographic and clinical data. The diagnostic procedure follows international guidelines (Wahlberg and Lindberg 2006) further refined by the German Contact Dermatitis Research Group (Schnuch et al. 2008), of which all IVDK participants are members. All data are transmitted to the data centre in Göttingen in an anonymous format twice yearly, where it is checked and, if satisfying internal quality control criteria (Uter et al. 2005), analysed according to international guidelines (Uter et al. 2004b) using SAS $^{\text {TM }}$ software (version 9.2, SAS Institute, Cary, NC).

For the present analysis, data of all patients patch tested between $01 / 1992$ and $12 / 2006$ with thiuram mix $1 \%$ in petrolatum (Hermal, Reinbek, Germany), as a part of the DKG baseline series, were included ( $n=121,051)$. Weak ("+") to strong ("+++") positive patch test reactions on the 3rd day after application of the test or, if this was not read, after the 4th day were aggregated as outcome "positive" and contrasted to non-positive (non-allergic) reactions, comprising negative, doubtful $(0.69 \%)$ and irritant $(0.05 \%)$ reactions. After descriptive bivariate analyses, a multifactorial analysis (Poisson regression analysis) was performed to adjust for a number of potential confounding factors. Job titles are originally documented in 3-digit precision based on the slightly expanded classification of the German Statistical Service and Labour Office, respectively (Anonymous 1992) with $n=493$ categories. For the present analysis, these job titles were aggregated to 27 occupations and occupational groups, respectively, included in the model along with 14 anatomical sites, age (categorised according to the quartiles of the age in our sample), sex, period of patch test, atopic dermatitis (past or present) and the number of additional positive reactions to allergens of the "baseline series". The adjusted prevalence ratios (PRs) $(95 \%$ confidence intervals $(95 \% \mathrm{CI}))$ were derived from the parameter estimates of the Poisson model to quantify the strength of association between single factors and the outcome.

\section{Results}

The overall prevalence of positive reactions to the thiuram mix was $2.38 \%$ (exact $95 \%$ CI: $2.29-2.47 \%$ ), with additional $0.69 \%$ doubtful and $0.05 \%$ irritant patch test reactions not considered positive (allergic). In a first descriptive analysis, the variation of contact allergy to the thiuram mix across the occupational groups was addressed-see Table 1.

Evidently, the crude prevalence varies considerably across the occupations and occupational groups, respectively. To examine the selection of patients from different occupations, those patients consulting German IVDK departments were addressed (disregarding the 6,718 Austrian and Swiss patients). The average annual number of consultations per occupation served as the numerator, and the denominator was the number of persons employed in the respective occupational categories covered by the German statutory social security in 1999 (the central year of the study period). The proportion is given as per mille in the second right column of Table 1; considerable differences of almost one order of magnitude can be observed. There was no significant correlation between this proportion and the crude prevalence of positive patch test reactions to the thiuram mix in the German subgroup (Spearman rank correlation coefficient: $0.25, p=0.24$ ).

In a next step, the multifactorial analysis yielded estimates of the relative risk in terms of PRs, which were mutually adjusted for all other factors included in the model. Several of these factors were associated with a significantly increased risk of contact allergy to the thiuram mix (Tables 2, 3). Although the role of occupational exposures is in the focus of this paper, the other factors are nevertheless of interest and are thus shown (Table 2). While female sex and past or present atopic dermatitis were associated with a minute, 11 and $16 \%$ elevation of risk, a considerable age gradient of sensitisation risk can be observed, with risk almost doubled in the oldest age group. Interestingly, the overall risk of contact sensitisation to the thiuram mix apparently declined during the study period ( $p$ for trend $<0.0001$ ). Among the anatomical sites of dermatitis, the hands are associated with the highest risk, followed by arms, legs and feet.

Many occupations and occupational groups, respectively, were associated with a significantly increased risk of contact allergy to the thiuram mix. It should be noted, 
Table 1 Crude prevalences of contact allergy to the thiuram mix, defined as "at least a weak positive reaction (+)" in different occupations

\begin{tabular}{|c|c|c|c|c|}
\hline ISCO- $88^{\mathrm{a}}$ & Job title/group & $n$ tested & $\begin{array}{l}0 / 00^{\mathrm{b}} \\
\text { per year }\end{array}$ & $\%+-+++$ \\
\hline 8231 & Rubber industry workers & 81 & 0.113 & 7.41 \\
\hline $2221,2222,3225,(7310)$ & Physicians and dentists & 1,900 & 0.729 & 5.74 \\
\hline $7143,(9130,9442)$ & Cleaners & 2,336 & 0.167 & 5.57 \\
\hline 7411 & Meat and fish processors & 436 & 0.229 & 5.05 \\
\hline 3230 & Nursing occupations & 5,412 & 0.247 & 4.92 \\
\hline $7121-3,7131-5,7320,9312-3$ & Construction and ceramic workers & 1,760 & 0.099 & 4.72 \\
\hline 2230,3231 & Geriatric nurses & 934 & 0.179 & 4.71 \\
\hline$(5220,5230), 6113,6141,9212$ & Florists, forestry workers & 967 & 0.180 & 4.45 \\
\hline $7430,7440,(5200), 8265,8266$ & Textile or leather worker or salesperson & 887 & 0.270 & 3.95 \\
\hline 5122,7414 & Cooks, food preparers & 1,434 & 0.178 & 3.63 \\
\hline $6110,6120,6151-3,(6200,9211)$ & Farmers, animal keepers & 788 & 0.296 & 3.17 \\
\hline $2224,3221,3223$ & Pharmacist, medical auxiliary personnel & 1,230 & 0.361 & 3.01 \\
\hline 5141 & Hairdressers, cosmetologists & 2,064 & 0.716 & 2.47 \\
\hline $3111,3116,3131,7344,8150,8220,8224$ & Chemical industry and photo lab workers & 984 & 0.159 & 2.34 \\
\hline- & Old age pensioners, students & 39,451 & - & 2.33 \\
\hline 3226 & Masseurs, physiotherapists & 580 & 0.321 & 2.24 \\
\hline 8110,9311 & Miners & 376 & 0.133 & 2.13 \\
\hline 8232 & Plastic material workers & 763 & 0.199 & 2.10 \\
\hline $\begin{array}{l}0000,3450,4142,4211,4212,5160,5220 \\
\quad 5230,8300,9110,9151,9152,9322,9333\end{array}$ & Sales and related service workers & 6,102 & 0.087 & 2.08 \\
\hline 5121,5123 & $\begin{array}{l}\text { Household }(n=12,822) \text { and } \\
\quad \text { guest service workers }(n=940)\end{array}$ & 13,762 & 0.178 & 1.91 \\
\hline $\begin{array}{c}2142-2147,7136,7212,7213,7222,7224 \\
7231-7233,7311,8120,8211,8223\end{array}$ & Metal workers & 6,063 & 0.127 & 1.86 \\
\hline 7412 & Bakers and confectioners & 766 & 0.402 & 1.83 \\
\hline $7311,7343,7346,8142,8143$ & Paper and printing industry workers & 511 & 0.121 & 1.57 \\
\hline $7137,7240,8282,8283$ & Technicians & 3,626 & 0.090 & 1.52 \\
\hline $2450,3470,7124,7141,7142,7331,7420,8141$ & Painters, carpenters, artists & 1,901 & 0.133 & 1.26 \\
\hline $1000,2300,4000$, and others & Office occupations and teachers & 18,468 & 0.125 & 1.25 \\
\hline
\end{tabular}

${ }^{\mathrm{a}}$ (Sub-) major and minor groups padded with trailing zeros

b Average number of consultations of all 15 years in the German departments related to 1999 statistics of workers employed in the respective occupation(s) according to "Bundesagentur für Arbeit" (Federal Labour Office, http://www.pub.arbeitsagentur.de/hst/services/statistik/detail_2004/ b.html, last accessed 2009-07-23)

however, that although the ranking of risk estimates is definite, the actual values of these estimates depend on the definition of the reference group. In this case, office workers and teachers were selected as a prototypically "unexposed" reference group, i.e., with a low a priori expected risk. Hence, all risk estimates are above 1. Largely, the ranking according to adjusted PR estimates is in accordance with the ranking based on crude prevalence, with a few exceptions indicative of some confounding.

After identifying three occupational subgroups with a relatively high risk of contact sensitisation to the thiurams, namely healthcare workers (physicians, nurses and related), food processors (cooks, meat and fish processors) and professional cleaners, the issue of a possible differential time trend was addressed. In view of (i) a distinct general risk gradient related to age (Table 2) and (ii) a weak, but significant association between age and year of patch test in the IVDK population (Uter et al. 2008), simple bivariate analyses of crude sensitisation prevalence across time were avoided. Instead, three separate Poisson regression models including age as confounder and the year of patch test as exposure of interest were used to identify a significant decline of sensitisation prevalence in case of healthcare workers ( $p$ for trend $=0.0008$ ), but no significant trend for the other two subgroups. The time course of age-standardised sensitisation prevalences is shown in Fig. 1a for healthcare workers and in Fig. 1b for the two other occupational groups. 
Table 2 Results of a Poisson regression analysis of 121,051 patients' data, collected between 1992 and 2006 by the IVDK network

\begin{tabular}{|c|c|c|c|}
\hline Variable & $\%$ & PR & $95 \% \mathrm{CI}$ \\
\hline Sex: female & 63.05 & 1.11 & $1.01-1.21$ \\
\hline Atopic eczema (past or current) & 18.30 & 1.16 & $1.05-1.28$ \\
\hline \multicolumn{4}{|l|}{ Age group } \\
\hline$\leq 32$ & 25.95 & 1.00 & (reference) \\
\hline $33-46$ & 23.19 & 1.48 & $1.32-1.66$ \\
\hline $47-60$ & 25.25 & 1.81 & $1.62-2.03$ \\
\hline$\geq 61$ & 25.60 & 1.87 & $1.63-2.14$ \\
\hline \multicolumn{4}{|l|}{ Study period } \\
\hline 1992-1996 & 31.62 & 1.00 & (reference) \\
\hline 1997-2001 & 34.17 & 0.81 & $0.74-0.89$ \\
\hline 2002-2006 & 34.22 & 0.77 & $0.70-0.85$ \\
\hline \multicolumn{4}{|l|}{ Anatomical site } \\
\hline Trunk & 3.61 & 1.00 & (reference) \\
\hline Axillae & 0.78 & 0.43 & $0.15-0.99$ \\
\hline $\operatorname{Arm}(\mathrm{s})$ & 3.83 & 1.55 & $1.11-2.19$ \\
\hline Hand(s) & 29.04 & 3.15 & $2.41-4.21$ \\
\hline Anogenital & 2.56 & 0.62 & $0.36-1.02$ \\
\hline $\operatorname{Leg}(s)$ & 10.53 & 1.54 & $1.16-2.09$ \\
\hline Foot/feet & 3.49 & 1.53 & $1.09-2.17$ \\
\hline Neck & 1.32 & 0.84 & $0.47-1.42$ \\
\hline Face & 15.73 & 1.02 & $0.76-1.39$ \\
\hline Scalp & 3.00 & 0.69 & $0.43-1.07$ \\
\hline Flexures & 0.51 & 1.21 & $0.53-2.41$ \\
\hline Generalised & 8.40 & 1.23 & $0.90-1.70$ \\
\hline "Other" site & 8.66 & 0.71 & $0.50-1.01$ \\
\hline \multicolumn{4}{|c|}{ Number of additional contact allergies } \\
\hline None & 54.38 & 1.00 & (reference) \\
\hline 1 & 23.84 & 2.28 & $2.05-2.53$ \\
\hline 2 & 11.87 & 3.60 & $3.22-4.02$ \\
\hline 3 & 5.56 & 4.39 & $3.85-5.01$ \\
\hline 4 or more & 4.34 & 6.98 & $6.17-7.89$ \\
\hline
\end{tabular}

Risk quantified with the prevalence ratio (PR), accompanied by a $95 \%$ confidence interval (CI)-first part: non-occupational factors

\section{Discussion}

Thiurams and dithiocarbamates, which are also represented by the thiuram mix in patch testing (Andersen et al. 2006), are important constituents of natural and synthetic rubber products. The vulcanisers (accelerators) may occur both in occupational and non-occupational context (e.g., in privately used "household gloves" (Proksch et al. 2009)). A considerable amount of unreacted accelerator-be it thiurams or other classes-remains in the cured rubber product, migrates to the surface and comes into contact with the skin. At least in thin products such as gloves or condoms, it
Table 3 Results of a Poisson regression analysis of 121,051 patients' data, collected between 1992-2006 by the IVDK network

\begin{tabular}{|c|c|c|c|}
\hline Occupation/occupational group & $\%$ & PR & $95 \% \mathrm{CI}$ \\
\hline Office occupations and teachers & 15.66 & 1.00 & (reference) \\
\hline Rubber industry workers & 0.07 & 5.09 & $2.00-10.48$ \\
\hline Physicians and dentists & 1.60 & 3.82 & $3.02-4.8$ \\
\hline Meat and fish processors & 0.37 & 3.48 & $2.16-5.31$ \\
\hline Cleaners & 1.99 & 3.09 & $2.48-3.84$ \\
\hline Nursing occupations & 4.58 & 2.96 & $2.47-3.56$ \\
\hline Florists, forestry workers & 0.82 & 2.74 & $1.94-3.77$ \\
\hline Construction and ceramic workers & 1.50 & 2.68 & $2.05-3.48$ \\
\hline Textile workers & 0.75 & 2.49 & $1.70-3.52$ \\
\hline Geriatric nurses & 0.80 & 2.27 & $1.61-3.12$ \\
\hline Cooks, food preparers & 1.22 & 2.21 & $1.60-2.97$ \\
\hline Medical auxiliary personnel & 1.04 & 2.09 & $1.45-2.94$ \\
\hline Farmers, animal keepers & 0.68 & 2.07 & $1.33-3.06$ \\
\hline Old age pensioners, students & 33.48 & 1.82 & $1.55-2.13$ \\
\hline $\begin{array}{l}\text { Chemical industry and photo } \\
\text { lab workers }\end{array}$ & 0.83 & 1.55 & $0.95-2.39$ \\
\hline Sales and related service workers & 5.20 & 1.47 & $1.18-1.83$ \\
\hline Miners & 0.32 & 1.44 & $0.65-2.73$ \\
\hline Plastic material workers & 0.65 & 1.42 & $0.82-2.29$ \\
\hline Hairdressers, cosmetologists & 1.75 & 1.37 & $0.99-1.85$ \\
\hline Household and guest service workers & 11.74 & 1.34 & $1.11-1.61$ \\
\hline Technicians & 3.06 & 1.25 & $0.92-1.68$ \\
\hline Metal workers & 5.17 & 1.21 & $0.95-1.53$ \\
\hline Bakers and confectioners & 0.66 & 1.18 & $0.64-1.99$ \\
\hline Masseurs & 0.49 & 1.17 & $0.62-2.00$ \\
\hline Paper and printing industry workers & 0.44 & 1.03 & $0.46-1.94$ \\
\hline Painters, carpenters & 1.60 & 1.00 & $0.64-1.50$ \\
\hline
\end{tabular}

Risk quantified with the prevalence ratio (PR), accompanied by a $95 \%$ confidence interval (CI)-second part: occupational factors

is possible to reduce the residual amount, and, with it, dermal exposure, by washing with hot water to create a product, which is more or less "hypoallergenic" in this respect (Andersen et al. 2006). Although rubber products, in particular, rubber gloves, constitute the major part of dermal exposure, additional rather limited skin contact with thiurams may also be due (i) to pesticides (Saunders and Watkins 2001), (ii) fungicides, also in paints and (iii) to animal repellents (Andersen et al. 2006).

Before addressing single findings of our unprecedented multifactorial analysis, the issue of differential selection of patients presenting for patch testing in one of the German IVDK centres has to be addressed. There are probably several reasons for an apparently varying likelihood of presenting:

- The risk of contact dermatitis varies between occupations, and with it, the proportion of workers consulting a dermatologist. The hairdressing trade is one example of a 

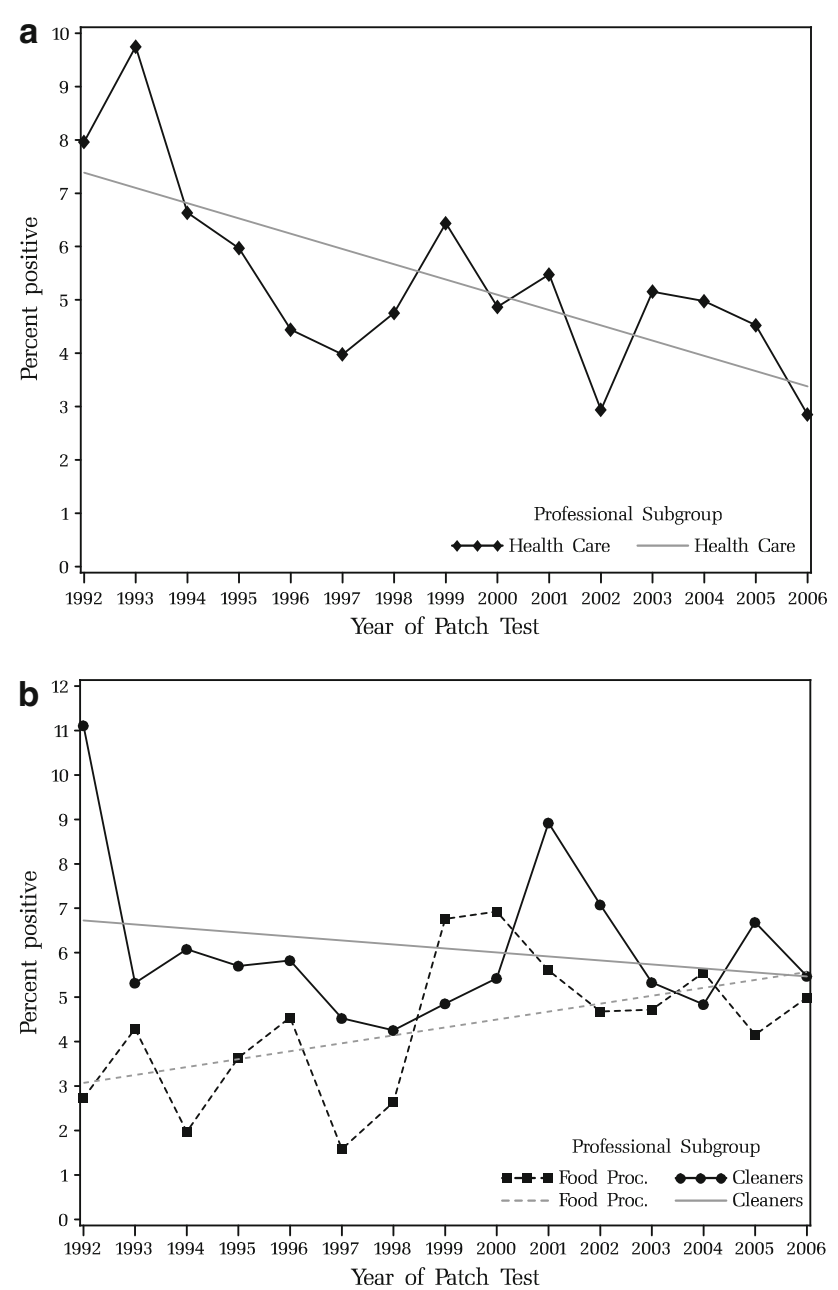

Fig. 1 a Time trend of sensitisation to the thiuram mix in healthcare workers. Sensitisation prevalence is directly age standardised. Straight grey line represents the fitted regression line to represent a linear subgroup-specific trend. $\mathbf{b}$ Time trend of sensitisation to the thiuram mix in food handlers and cleaners, respectively. Sensitisation prevalence is directly age standardised. Straight grey lines represent fitted regression lines to represent a linear subgroup-specific trend

high-risk occupation, be it in terms of (primary) irritant contact dermatitis.

- The accessibility to health care may vary between occupations: physicians and dentists, but also other healthcare personnel may find it easier to access a contact dermatitis clinic than, for instance, manual labourers.

- As only workers covered by statutory social security are included in the denominator, whereas the numerator includes privately insured patients, professions with a higher percentage of privately insured persons will bias the proportion of consultations upward.

However, the contribution of these factors to overall or specific occupation selection cannot be reconciled well. Hence, our analysis could not incorporate such factors effectively, and the interpretation of our findings based on a sample that is not representative of the whole (diseased) population has to be cautious. Still, the fact that no correlation exists between the prevalence of contact sensitisation to thiuram mix and the "selection probability" could indicate that while some selection is occurring, this may not, or at least only to a small degree, be driven by the specific morbidity considered here, namely, contact allergy to thiurams.

From the background of known sources of allergen exposure, some results are very plausible, while some other results warrant further in-depth investigation:

- The highest risk has been found in the very small group of rubber industry workers-probably the only profession that may even be exposed to the compounds directly, and not only by leaching from finished rubber products.

- A number of occupations in health care are associated with a high risk of sensitisation to the thiurams, in accordance with previous observations. In these cases, protective gloves constitute the source of allergens. Interestingly, in this occupation, a significant and very marked downward trend can be observed, as recently reported in London patients (Bhargava et al. 2009) and from Denmark (Knudsen et al. 2006), probably reflecting broader availability of higher quality gloves leaching less thiurams or dithiocarbamates or containing other vulcanising agents such as benzothiazoles. As a novel finding, food handlers have an elevated risk, which is-albeit not significantly_increasing rather than decreasing (see dashed line in Fig. 1). As at least partly protective gloves have no proven beneficial effect, compared to standard hand hygiene in terms of prevention of microbial contamination (Lynch et al. 2005), current practice in this area possibly needs to be (re-)examined.

- Professional cleaners (mostly room cleaners) also have an elevated risk. This is interesting and warrants further investigation, as thick, "household" type gloves, often lined with cotton, have been considered as relatively safe so far (Proksch et al. 2009)-however, possibly the usage of thin, single-use rubber gloves contributes to the burden of contact allergy in this area. The very slight (non-significant) decline observed in this subgroup may have similar reasons as in the healthcare sector, where thin, single-use gloves by far dominate.

- The fact that construction workers (but not painters and carpenters) who are unlikely to wear (thin single-use) (natural latex) rubber gloves have an increased risk of contact to thiurams (Uter et al. 2004a) is noteworthy. Other sources of exposure to thiurams that may exist need to be identified.

- Use of protective gloves, but also exposure to fungicides, may be the reason of an elevated risk noted in persons handling plants (and partly animals). 
In previous observation (Andersen et al. 2006), females did not have a relevantly increased risk in our adjusted analysis. Most likely, any previous bivariate, unadjusted analysis will have been confounded by a sex-specific occupational pattern. Among the clinical factors considered, the predominance of exposure via gloves is illustrated by the pattern of sites associated with an increased risk. Interestingly, footwear seems to have some relevance for elicitation of contact dermatitis due to thiurams as well. The general slow, but steady decline of risk across our study period may indicate lesser usage of thiurams, as found previously in a highly selected subset of patients tested for a priori suspected occupational rubber glove allergy, which have apparently been replaced by benzothiazoles or dithiocarbamates (Geier et al. 2003) - the latter presumably weakening the downward trend due to considerable cross-reactivity with thiurams.

\section{Conclusion}

Although the decline over time of contact sensitisation to thiurams is encouraging, the prevalence of contact allergy in a number of occupations is still high, with increased risk verified by an adjusted, multifactorial analysis. In most occupations, single- or multiple-use, natural or synthetic rubber gloves are the most important, or even only, source of exposure. If protective gloves are a necessary component of personal protection with proven effectiveness, we suggest minimising the amount of thiurams or dithiocarbamates to further reduce the risk of contact allergy to these compounds.

Conflict of interest The authors declare that they have no conflict of interest.

Open Access This article is distributed under the terms of the Creative Commons Attribution Noncommercial License which permits any noncommercial use, distribution, and reproduction in any medium, provided the original author(s) and source are credited.

\section{Appendix}

The centres are listed in alphabetical order.

Aachen (C. Schröder, H. Dickel, S. Erdmann), Augsburg (A. Ludwig), Basel (A. Bircher), Berlin B.-Frank. (B. Tebbe, M. Worm, R. Treudler), Berlin BWK (A. Köhler), Berlin Charité (B. Laubstein, M. Worm, T. Zuberbier), Berlin UKRV (J. Grabbe, T. Zuberbier), Bern (D. Simon), Bielefeld (I. Effendy), Bochum (Ch. Szliska, H. Dickel, M. Straube), Dermatologikum (K. Reich, V. Martin), Dortmund (B. Pilz, C. Pirker, K. Kügler, P.J. Frosch, R. Herbst), Dresden (G. Richter, P. Spornraft-Ragaller, R. Aschoff),
Duisburg (J. Schaller), Erlangen (K.-P. Peters, M. Fartasch, M. Hertl, T.L. Diepgen, V. Mahler), Essen (H.-M. Ockenfels, J. Schaller, U. Hillen), Freudenberg (Ch. Szliska), Geier, Göttingen (J. Geier), Gera (J. Meyer), Graz (B. Kränke, W. Aberer), Greifswald (M. Jünger), Göttingen (J. Geier, Th. Fuchs), Halle (B. Kreft, D. Lübbe, G. Gaber), Hamburg (D. Vieluf, E. Coors, M. Kiehn, R. Weßbecher), Hannover (T. Schaefer, Th. Werfel), Heidelberg (A. Schulze-Dirks, M. Hartmann, U. Jappe), Heidelberg AKS (E. Weisshaar, H. Dickel, T.L. Diepgen), Homburg/Saar (C. Pföhler, F.A. Bahmer, P. Koch), Jena (A. Bauer, M. Gebhardt, M. Kaatz, S. Schliemann-Willers, W. WiggerAlberti), Kiel (J. Brasch), Krefeld (A. Wallerand, M. Lilie, S. Wassilew), Lübeck (J. Grabbe, J. Kreusch, K.P. Wilhelm), Mainz (D. Becker), Mannheim (Ch. Bayerl, D. Booken, H. Kurzen), Marburg (H. Löffler, I. Effendy, M. Hertl), München LMU (B. Przybilla, F. Enders, F. Rueff, P. Thomas, R. Eben, T. Oppel, T. Schuh), München Schwabing (K. Ramrath, M. Agathos), München TU (J. Rakoski, U. Darsow), Münster (B. Hellweg, R. Brehler), Nürnberg (A. Hohl, D. Debus, I. Müller), Osnabrück (Ch. Skudlik, H. Dickel, H.J. Schwanitz (+), N. Schürer, S.M. John, W. Uter), Rostock (Ch. Schmitz, H. Heise, J. Trcka, M.A. Ebisch), Tübingen (G. Lischka, M. Röcken, T. Biedermann), Ulm (G. Staib, H. Gall (+), P. Gottlöber), Ulm, BWK (H. Pillekamp), Wuppertal (J. Raguz, O. Mainusch), Würzburg (A. Trautmann, J. Arnold).

\section{References}

Andersen KE et al (2006) Allergens from the standard series. In: Frosch P et al (eds) Contact dermatitis. Springer, Berlin, pp 453-492

Belsito DV (2000) Rubber. In: Kanerva L et al (eds) Handbook of occupational dermatology. Springer, Berlin, pp 701-718

Bhargava K et al (2009) Thiuram patch test positivity 1980-2006: incidence is now falling. Contact Dermatitis 60:222-223. doi:10.1111/j.1600-0536.2008.01358.x

Geier J et al (2003) Occupational rubber glove allergy: results of the Information Network of Departments of Dermatology (IVDK), 1995-2001. Contact Dermatitis 48:39-44. doi:10.1034/j.16000536.2003.480107.x

Knudsen BB et al (2006) Reduction in the frequency of sensitization to thiurams. A result of legislation? Contact Dermatitis 54:170-171. doi:10.1111/j.0105-1873.2005.0739c.x

Lynch RA et al (2005) A preliminary evaluation of the effect of glove use by food handlers in fast food restaurants. J Food Prot 68:187-190

Proksch E et al (2009) Presumptive frequency of, and review of reports on, allergies to household gloves. J Eur Acad Dermatol Venereol 23:388-393. doi:10.1111/j.1468-3083.2008.03061.x

Saunders H, Watkins F (2001) Allergic contact dermatitis due to thiuram exposure from a fungicide. Australas J Dermatol 42:217218. doi:10.1111/j.1440-0960.2001.00523.x

Schnuch A et al (2008) Patch testing with contact allergens. J Dtsch Dermatol Ges 6:770-775. doi:10.1111/j.1610-0387.2009.06787.x

Uter W et al (2004a) Contact allergy in construction workers: results of a multifactorial analysis. Ann Occup Hyg 48:21-27. doi:10.1093/annhyg/meg080 
Uter W et al (2004b) Guidelines for the descriptive presentation and statistical analysis of contact allergy data. Contact Dermatitis 51:47-56. doi:10.1111/j.0105-1873.2004.00406.x

Uter W et al (2005) Interne qualitätssicherung von epikutantest-daten des multizentrischen projektes "Informationsverbund Dermatologischer Kliniken” (IVDK). Derm Beruf Umwelt 53:107-114
Uter W et al (2008) Changes of the patch test population (MOAHLFA index) in long-term participants of the Information Network of Departments of Dermatology, 1999-2006. Contact Dermatitis 59:56-57. doi:10.1111/j.1600-0536.2007.01313.x

Wahlberg JE, Lindberg M (2006) Patch Testing. In: Frosch PJ et al (eds) Contact dermatitis. Springer, Berlin, pp 365-390 